\title{
Multi-gene phylogeny and divergence estimations for Evaniidae (Hymenoptera)
}

\author{
Barbara J Sharanowski ${ }^{1}$, Leanne Peixoto ${ }^{2}$, Anamaria Dal Molin ${ }^{3}$, Andrew R Deans ${ }^{\text {Corresp. } 4}$ \\ 1 Department of Biology, University of Central Florida, Orlando, Florida, United States \\ 2 Department of Agroecology, Aarhus University, Aarhus, Denmark \\ 3 Departamento de Ciências Biológicas, Universidade Federal do Espírito Santo, Vitória, ES, Brazil \\ 4 Frost Entomological Museum, Department of Entomology, Pennsylvania State University, University Park, PA, United States \\ Corresponding Author: Andrew R Deans \\ Email address: adeans@psu.edu
}

Ensign wasps (Hymenoptera: Evaniidae) develop as predators of cockroach eggs (Blattodea), have a wide distribution and exhibit numerous interesting biological phenomena. The taxonomy of this lineage has been the subject of several recent, intensive efforts, but the lineage lacked a robust phylogeny. In this paper we present a new phylogeny, based on increased taxonomic sampling and data from six molecular markers (mitochondrial 165 and COI, and nuclear markers 28S, RPS23, CAD, and AM2), the latter used for the first time in phylogenetic reconstruction. Our intent is to provide a robust phylogeny that will stabilize and facilitate revision of the higher-level classification. We also show the continued utility of molecular motifs, especially the presence of an intron in the RPS23 fragments of certain taxa, to diagnose evaniid clades and assist with taxonomic classification. Furthermore, we estimate divergence times among evaniid lineages for the first time, using multiple fossil calibrations. Evaniidae radiated primarily in the Early Cretaceous (134.1-141.1 Mya), with and most extant genera diverging near the $\mathrm{K}-\mathrm{T}$ boundary. The estimated phylogeny reveals a more robust topology than previous efforts, with the recovery of more monophyletic taxa and better higher-level resolution. The results facilitate a change in ensign wasp taxonomy, with Parevania, syn. nov., and Papatuka, syn. nov. becoming junior synonyms of Zeuxevania, and Acanthinevania, syn. nov. being designated as junior synonym of Szepligetella. We transfer 30 species to Zeuxevania, either reestablishing past combinations or as new combinations. We also transfer 20 species from Acanthinevania to Szepligetella as new combinations. 


\title{
Multi-gene phylogeny and divergence time estimations for Evaniidae (Hymenoptera)
}

\author{
Barbara J. Sharanowski ${ }^{1}$, Leanne Peixoto ${ }^{2}$, Anamaria Dal Molin ${ }^{3}$, and \\ Andrew R. Deans ${ }^{4}$ \\ ${ }^{1}$ University of Central Florida, Department of Biology, 4110 Libra Drive, BIO 301, \\ Orlando, Florida, USA 32816-2368 \\ ${ }^{2}$ Aarhus University, Department of Agroecology, Aarhus, Denmark, AU Foulum, \\ Blichers Allé 208830 Tjele \\ ${ }^{3}$ Depto. Ciências Biológicas, Universidade Federal do Espirito Santo, Vitória, ES, Brazil \\ ${ }^{4}$ Frost Entomological Museum, Department of Entomology, 501 ASI Building, \\ Pennsylvania State University, University Park, PA USA 16802 \\ Corresponding author: \\ Andrew R. Deans ${ }^{4}$ \\ Email address: adeans@psu.edu
}

\section{ABSTRACT}

Ensign wasps (Hymenoptera: Evaniidae) develop as predators of cockroach eggs (Blattodea), have a wide distribution and exhibit numerous interesting biological phenomena. The taxonomy of this lineage has been the subject of several recent, intensive efforts, but the lineage lacked a robust phylogeny. In this paper we present a new phylogeny, based on increased taxonomic sampling and data from six molecular markers (mitochondrial 16S and COI, and nuclear markers 28S, RPS23, CAD, and AM2), the latter used for the first time in phylogenetic reconstruction. Our intent is to provide a robust phylogeny that will stabilize and facilitate revision of the higher-level classification. We also show the continued utility of molecular motifs, especially the presence of an intron in the RPS23 fragments of certain taxa, to diagnose evaniid clades and assist with taxonomic classification. Furthermore, we estimate divergence times among evaniid lineages for the first time, using multiple fossil calibrations. Evaniidae radiated primarily in the Early Cretaceous (134.1-141.1 Mya), with and most extant genera diverging near the K-T boundary. The estimated phylogeny reveals a more robust topology than previous efforts, with the recovery of more monophyletic taxa and better higher-level resolution. The results facilitate a change in ensign wasp taxonomy, with Parevania, syn. nov., and Papatuka, syn. nov. becoming junior synonyms of Zeuxevania, and Acanthinevania, syn. nov. being designated as junior synonym of Szepligetella. We transfer 30 species to Zeuxevania, either reestablishing past combinations or as new combinations. We also transfer 20 species from Acanthinevania to Szepligetella as new combinations.

\section{INTRODUCTION}

Ensign wasps (Hymenoptera: Evaniidae) are common, nearly cosmopolitan, and include approximately 500 extant species in 21 genera, although many species remain to be described (Deans, 2005). Their biology lies at the precipice between wasps that provision their young with prey and parasitic wasps that deposit their offspring to feed on one host. A female evaniid wasp lays a single egg within a cockroach egg case and their offspring feeds on the unhatched cockroach eggs. Because their larvae feed on multiple hosts, ensign wasps are regarded as predators as opposed to parasitoids (Huben. 1995). However, the intimate association that larval evaniids have with their prey is much more reminiscent of parasitoid behavior. Despite these interesting biological features, there is scant research aimed at understanding their evolution and natural history. This predicament remains, in part, due to ongoing instability in their classification and the lack of robust diagnostic tools and inadequate taxon descriptions. Taxonomic work over the last 20 years, however, including a key to genera (Deans and Huben, 2003), a comprehensive species catalog (Deans, 2005, treating all ca. 500 species), descriptions of fossils (Deans et al., 2004; Jennings et al., 2013, 2012, 2004), and updated (Deans and Kawada, 2008) and semantically-enhanced 
species-level revisions (Balhoff et al., 2013, Mikó et al., 2014) have substantially increased the potential for research on these insects.

Deans et al. (2006) also published the first phylogeny of the family, which was an attempt to test the historic generic and tribal classifications. Of the 17 included genera, four were represented by single specimens: Papatuka Deans, Rothevania Huben (monotypic), Thaumatevania Ceballos (monotypic), and Trissevania Kieffer. Six genera were found to be monophyletic in both a parsimony and Bayesian analysis, including: Acanthinevania Bradley, Decevania Huben, Evania Fabricius, Evaniscus Szépligeti, Micrevania Benoit, and Semaeomyia Bradley. Although Prosevania Kieffer was always recovered, with one possibly misplaced specimen of Szepligetella Bradley, it is likely that Prosevania may also be monophyletic. Several other genera were consistently recovered as paraphyletic or in unresolved polytomies, including Brachygaster Leach, Evaniella Bradley, Hyptia Illiger, Szepligetella Bradley, Parevania Kieffer, and Zeuxevania Kieffer. The latter two genera were consistently recovered in a clade with Papatuka Deans, and Deans et al. (2006) suggested that these taxa may be congeneric based on the molecular results and inconsistencies in the morphological character that separates these two genera (presence of fore wing 1RS in Parevania). They also suggested Evaniella may be monophyletic as it was consistently recovered with the exception of one aberrant taxon, since described as its own genus (Alobevania Deans and Kawada, 2008)).

The only tribal classification put forth for Evaniidae was by Bradley (1908), who suggested two tribes for the ten genera described at the time: Hyptiini (including Evaniella, Evaniscus, Hyptia, Parevania, Semaeomyia, and Zeuxevania) and Evaniini (including Acanthinevania, Evania, Prosevania, and Szepligetella). This tribal classification was not supported by Deans et al. (2006). There was not enough resolution to confidently resolve relationships among evaniid genera to develop a better tribal classification. Deans et al. (2006) did suggest that the New World taxa with reduced wing venation (including Evaniscus, Decevania, Hyptia, Rothevania, and Semaeomyia) were monophyletic and could represent a tribe.

The poorly resolved phylogenies published by Deans et al. (2006) may be attributed to low taxonomic sampling, as only 54 ingroup taxa were included, or, more likely, a lack of informative sites in the sequence data. The resulting "backbone polytomy", where higher-level classifications remain elusive, is common in other phylogenies of Hymenoptera that use the same or similar sets of genes (Dowton and Austin, 2001, Mardulyn and Whitfield, 1999, Pitz et al., 2007). Divergence times for members of Evaniidae have not been estimated before. Several recent studies on Hymenoptera have estimated stem-age divergences for Evanioidea ranging from $175 \mathrm{Ma}$ to $221 \mathrm{Ma}$ (Ronquist et al., 2012a; Zhang et al., 2015; Peters et al. 2017, Branstetter et al., 2017). Unfortunately, the small sample size for Evanioidea in all of these studies (1-3 exemplars) and uncertainty in phylogenetic relationships of Evanioidea within Hymenoptera resulted in wide confidence intervals around the estimates. Based on all fossils placed within Evanioidea, it is likely that the superfamily diversified in the Middle Jurassic but may have originated as early as the late Triassic (Li et al., 2018).

Here we attempt to gain a better understanding of higher-level relationships among genera and better test the monophyly of genera, using an increased taxonomic and genetic sampling dataset, including a handful of new protein-coding genes. Our intent is to provide a robust phylogeny that will stabilize and facilitate revision of the higher-level classification. We also show the continued utility of molecular motifs, first described for Evaniidae by Deans et al. (2006), to diagnose clades and assist with taxonomic classification. Furthermore, we estimate divergence times among evaniid lineages for the first time, using multiple fossil calibrations to understand of the timing of diversification in Evaniidae.

\section{MATERIALS AND METHODS}

\section{Taxon sampling}

A list of taxa and sequences utilized in this study is presented in Table 1 (more details in Table S1). Exemplars were obtained for 89 evaniid specimens, across 17 genera, and five outgroup taxa, including two species of Gasteruption (Gasteruptiidae) and three species of Pristaulacus (Aulacidae), for a total of 94 taxa. All evaniid genera were represented except four rare genera: Afrevania, Brachevania, Thaumatevania, and Vernevania. We were only able to include one representative of Alobevania and Rothevania (monotypic), and Papatuka. Where possible, sampling was increased for genera that were previously recovered as paraphyletic by Deans et al. (2006). 


\begin{tabular}{|c|c|c|c|c|c|c|c|c|c|}
\hline taxon & Ext. & DV\# & $28 S$ & AM2 & CAD1 & CAD2 & RPS23 & COI & $16 S$ \\
\hline Gasteruption 300 & 300 & & $\mathrm{X}$ & & $\mathrm{X}$ & $\mathrm{X}$ & $\mathrm{X}$ & $\mathrm{X}$ & $\mathrm{D}$ \\
\hline Gasteruption 244 & 244 & & $\mathrm{X}$ & & $\mathrm{X}$ & & $\mathrm{X}$ & $\mathrm{X}$ & \\
\hline Pristaulacus strangaliae & 176 & & & $\mathrm{X}$ & & & $X$ & $X$ & \\
\hline Pristaulacus fasciatus & 299 & & & & & & & $\mathrm{X}$ & \\
\hline Pristaulacus 21 & 306 & 21 & $\mathrm{D}$ & & & & $\mathrm{X}$ & $\mathrm{D}$ & $\mathrm{D}$ \\
\hline Acanthinevania 240 & 240 & & $\mathrm{X}$ & $\mathrm{X}$ & $\mathrm{X}$ & $\mathrm{X}$ & $\mathrm{X}$ & $\mathrm{X}$ & \\
\hline Acanthinevania 242 & 242 & & $\mathrm{X}$ & $\mathrm{X}$ & $\mathrm{X}$ & $\mathrm{X}$ & $\mathrm{X}$ & & \\
\hline Acanthinevania princeps & 246 & & $\mathrm{X}$ & & $\mathrm{X}$ & $\mathrm{X}$ & $\mathrm{X}$ & $\mathrm{X}$ & \\
\hline Acanthinevania 001 & 271 & 001 & $\mathrm{D}$ & $\mathrm{X}$ & $\mathrm{X}$ & $\mathrm{X}$ & $\mathrm{X}$ & $\mathrm{D}$ & $\mathrm{D}$ \\
\hline Acanthinevania 033 & 289 & 033 & $\mathrm{D}$ & $\mathrm{X}$ & $\mathrm{X}$ & $\mathrm{X}$ & $\mathrm{X}$ & $\mathrm{D}$ & $\mathrm{D}$ \\
\hline Acanthinevania 049 & 292 & 049 & $\mathrm{D}$ & $\mathrm{X}$ & $\mathrm{X}$ & $\mathrm{X}$ & $\mathrm{X}$ & $\mathrm{D}$ & $\mathrm{D}$ \\
\hline Alobevania gattiae & 200 & 039 & $\mathrm{D}$ & $\mathrm{X}$ & $\mathrm{X}$ & $\mathrm{X}$ & & $\mathrm{X}$ & $\mathrm{D}$ \\
\hline Brachygaster minutus & 273 & 030 & $\mathrm{X}$ & & $\mathrm{X}$ & $\mathrm{X}$ & $\mathrm{X}$ & $\mathrm{D}$ & $\mathrm{D}$ \\
\hline Brachygaster minutus & 512 & & & & $\mathrm{X}$ & $\mathrm{X}$ & & $X$ & \\
\hline Brachygaster 037 & 286 & & D & & $\mathrm{X}$ & & $\mathrm{X}$ & & $\mathrm{D}$ \\
\hline Brachygaster 050 & 290 & & $\mathrm{D}$ & & & & $\mathrm{X}$ & & $\mathrm{D}$ \\
\hline Decevania 502 & 502 & & & & $\mathrm{X}$ & $\mathrm{X}$ & & & \\
\hline Decevania 513 & 513 & & & $\mathrm{X}$ & & & & $\mathrm{X}$ & \\
\hline Decevania 004 & 274 & 004 & $\mathrm{D}$ & $\mathrm{X}$ & & $\mathrm{X}$ & $\mathrm{X}$ & $\mathrm{D}$ & $\mathrm{D}$ \\
\hline Decevania 005 & 301 & 005 & $\mathrm{D}$ & & & & $\mathrm{X}$ & & $\mathrm{D}$ \\
\hline Decevania 063 & 296 & 063 & $\mathrm{D}$ & $\mathrm{X}$ & $\mathrm{X}$ & $\mathrm{X}$ & $\mathrm{X}$ & $\mathrm{D}$ & $\mathrm{D}$ \\
\hline Evania 175 & 175 & & $\mathrm{X}$ & & & & $\mathrm{X}$ & $\mathrm{X}$ & \\
\hline Evania albofacialis & 275 & 020 & $\mathrm{D}$ & & $\mathrm{X}$ & $\mathrm{X}$ & $\mathrm{X}$ & $\mathrm{D}$ & $\mathrm{D}$ \\
\hline Evania appendigaster & 207 & 046 & $\mathrm{D}$ & & $\mathrm{X}$ & $\mathrm{X}$ & $\mathrm{X}$ & $\mathrm{D}$ & $\mathrm{D}$ \\
\hline Evania 496 & 496 & & $\mathrm{X}$ & & & $\mathrm{X}$ & $\mathrm{X}$ & $\mathrm{X}$ & \\
\hline Evania 002 & 189 & 002 & $\mathrm{D}$ & & $\mathrm{X}$ & $\mathrm{X}$ & & $\mathrm{D}$ & $\mathrm{D}$ \\
\hline Evaniella 230 & 230 & & $\mathrm{X}$ & $\mathrm{X}$ & $\mathrm{X}$ & $\mathrm{X}$ & $X$ & $\mathrm{X}$ & \\
\hline Evaniella 234 & 234 & & $\mathrm{X}$ & $X$ & & $\mathrm{X}$ & $X$ & $\mathrm{X}$ & \\
\hline Evaniella 237 & 237 & & & $\mathrm{X}$ & $\mathrm{X}$ & & & $\mathrm{X}$ & \\
\hline Evaniella 485 & 485 & & & $\mathrm{X}$ & $\mathrm{X}$ & $\mathrm{X}$ & $\mathrm{X}$ & & \\
\hline Evaniella 486 & 486 & & & $\mathrm{X}$ & $\mathrm{X}$ & & $X$ & & \\
\hline Evaniella 493 & 493 & & & & $\mathrm{X}$ & & $X$ & $\mathrm{X}$ & \\
\hline Evaniella semaeoda & 220 & 058 & $\mathrm{D}$ & & & & $\mathrm{X}$ & $\mathrm{D}$ & $\mathrm{D}$ \\
\hline Evaniella 019 & 192 & 019 & $\mathrm{D}$ & $\mathrm{X}$ & $\mathrm{X}$ & & $\mathrm{X}$ & $\mathrm{D}$ & \\
\hline Evaniella 025 & 307 & 025 & $\mathrm{D}$ & & $\mathrm{X}$ & & $\mathrm{X}$ & $\mathrm{D}$ & $\mathrm{D}$ \\
\hline Evaniella 045 & 206 & 045 & $\mathrm{D}$ & $\mathrm{X}$ & $\mathrm{X}$ & & $\mathrm{X}$ & & $\mathrm{D}$ \\
\hline Evaniscus marginatus & 213 & 052 & $\mathrm{D}$ & & & & $\mathrm{X}$ & & $\mathrm{D}$ \\
\hline Evaniscus rufithorax & 206 & & $\mathrm{D}$ & & & $\mathrm{X}$ & $\mathrm{X}$ & $\mathrm{X}$ & $\mathrm{D}$ \\
\hline Hyptia 232 & 232 & & & $\mathrm{X}$ & $\mathrm{X}$ & $X$ & $X$ & $\mathrm{X}$ & \\
\hline Hyptia 487 & 487 & & & $\mathrm{X}$ & & & & $\mathrm{X}$ & \\
\hline Hyptia 501 & 501 & & & $\mathrm{X}$ & $\mathrm{X}$ & & & $\mathrm{X}$ & \\
\hline Hyptia 511 & 511 & & & $X$ & $\mathrm{X}$ & & & $\mathrm{X}$ & \\
\hline Hyptia amazonica & 235 & & & & $\mathrm{X}$ & $\mathrm{X}$ & & $\mathrm{X}$ & \\
\hline Hyptia floridana & 291 & 009 & $\mathrm{D}$ & $\mathrm{X}$ & $\mathrm{X}$ & $\mathrm{X}$ & & $\mathrm{D}$ & $\mathrm{D}$ \\
\hline Hyptia 007 & 302 & 007 & $\mathrm{D}$ & & $\mathrm{X}$ & & $\mathrm{X}$ & $\mathrm{D}$ & $\mathrm{D}$ \\
\hline Hyptia 008 & 303 & 008 & $\mathrm{D}$ & & & & $\mathrm{X}$ & $\mathrm{D}$ & $\mathrm{D}$ \\
\hline Micrevania difficilis & 283 & 006 & $\mathrm{D}$ & & $\mathrm{X}$ & $\mathrm{X}$ & & $\mathrm{X}$ & $\mathrm{D}$ \\
\hline Micrevania 061 & 288 & 061 & $\mathrm{D}$ & $\mathrm{X}$ & & $\mathrm{X}$ & & $\mathrm{D}$ & $\mathrm{D}$ \\
\hline Micrevania 066 & 298 & 066 & $\mathrm{D}$ & & & $\mathrm{X}$ & & $\mathrm{D}$ & $\mathrm{D}$ \\
\hline Micrevania 026 & 308 & 026 & $\mathrm{D}$ & & & $\mathrm{D}$ & & $\mathrm{D}$ & $\mathrm{D}$ \\
\hline Papatuka capensis & 227 & 065 & $\mathrm{D}$ & & $\mathrm{X}$ & $\mathrm{X}$ & $\mathrm{X}$ & $X$ & $\mathrm{D}$ \\
\hline Parevania 172 & 172 & & $X$ & $\mathrm{X}$ & $\mathrm{X}$ & & $X$ & & \\
\hline Parevania 174 & 174 & & $X$ & $\mathrm{X}$ & & & $X$ & $\mathrm{X}$ & \\
\hline
\end{tabular}


Table 1 - Continued from previous page

\begin{tabular}{|c|c|c|c|c|c|c|c|c|c|}
\hline taxon & Ext. & DV\# & 28S & AM2 & CAD1 & CAD2 & RPS23 & COI & $16 S$ \\
\hline Parevania 041 & 295 & 041 & $\mathrm{D}$ & $\mathrm{X}$ & $\mathrm{X}$ & $\mathrm{X}$ & $\mathrm{X}$ & $\mathrm{D}$ & $\mathrm{D}$ \\
\hline Parevania 057 & 219 & 057 & $\mathrm{D}$ & $\mathrm{X}$ & $\mathrm{X}$ & $X$ & $X$ & & $\mathrm{D}$ \\
\hline Parevania 064 & 276 & 064 & $\mathrm{D}$ & & $\mathrm{X}$ & $\mathrm{X}$ & $X$ & $\mathrm{D}$ & $\mathrm{D}$ \\
\hline Prosevania fuscipes & 224 & 062 & $\mathrm{D}$ & & & $\mathrm{X}$ & & $\mathrm{X}$ & $\mathrm{D}$ \\
\hline Prosevania 497 & 497 & & $\mathrm{X}$ & $\mathrm{X}$ & $\mathrm{X}$ & $\mathrm{X}$ & & $\mathrm{X}$ & \\
\hline Prosevania 498 & 498 & & & & $\mathrm{X}$ & & & $\mathrm{X}$ & \\
\hline Prosevania 508 & 508 & & & & & & & $\mathrm{X}$ & \\
\hline Prosevania 027 & 309 & 027 & $\mathrm{D}$ & X & & X & & $\mathrm{X}$ & $\mathrm{D}$ \\
\hline Prosevania 034 & 277 & 034 & $\mathrm{D}$ & & & & & $\mathrm{D}$ & $\mathrm{D}$ \\
\hline Prosevania 036 & 284 & 036 & $\mathrm{D}$ & & $X$ & $X$ & & $\mathrm{X}$ & $\mathrm{D}$ \\
\hline Prosevania 044 & 205 & 044 & $\mathrm{D}$ & $\mathrm{X}$ & $\mathrm{X}$ & $\mathrm{X}$ & $\mathrm{X}$ & $\mathrm{D}$ & $\mathrm{D}$ \\
\hline Rothevania valdivianus & 239 & 048 & $\mathrm{D}$ & $\mathrm{X}$ & $\mathrm{X}$ & $\mathrm{X}$ & & $\mathrm{D}$ & $\mathrm{D}$ \\
\hline Semaeomyia 489 & 489 & & & & $\mathrm{X}$ & $X$ & $\mathrm{X}$ & $\mathrm{X}$ & \\
\hline Semaeomyia 509 & 509 & & $\mathrm{X}$ & & & $\mathrm{X}$ & $\mathrm{X}$ & $\mathrm{X}$ & \\
\hline Semaeomyia 510 & 510 & & $\mathrm{X}$ & & & $X$ & $\mathrm{X}$ & $\mathrm{X}$ & \\
\hline Semaeomyia leucomelas & 305 & 016 & $\mathrm{D}$ & & & $\mathrm{X}$ & $\mathrm{X}$ & $\mathrm{D}$ & $\mathrm{D}$ \\
\hline Semaeomyia 012 & 197 & 012 & $\mathrm{D}$ & & $\mathrm{X}$ & $\mathrm{X}$ & & $\mathrm{D}$ & $\mathrm{D}$ \\
\hline Semaeomyia 051 & 279 & 051 & $\mathrm{D}$ & & & $X$ & $\mathrm{X}$ & $\mathrm{D}$ & $\mathrm{D}$ \\
\hline Semaeomyia 059 & 293 & 059 & $\mathrm{D}$ & $X$ & & $\mathrm{X}$ & $\mathrm{X}$ & $\mathrm{D}$ & $\mathrm{D}$ \\
\hline Szepligetella 170 & 170 & & & & X & & $\mathrm{X}$ & $\mathrm{X}$ & \\
\hline Szepligetella 231 & 231 & & $\mathrm{X}$ & & $\mathrm{X}$ & X & $\mathrm{X}$ & $\mathrm{X}$ & \\
\hline Szepligetella 233 & 233 & & $\mathrm{X}$ & $X$ & $\mathrm{X}$ & $\mathrm{X}$ & $\mathrm{X}$ & $\mathrm{X}$ & \\
\hline Szepligetella 236 & 236 & & $\mathrm{X}$ & $\mathrm{X}$ & $\mathrm{X}$ & $X$ & & $\mathrm{X}$ & \\
\hline Szepligetella 238 & 238 & & $\mathrm{X}$ & $\mathrm{X}$ & $\mathrm{X}$ & $\mathrm{X}$ & X & $\mathrm{X}$ & \\
\hline Szepligetella 241 & 241 & & & & $\mathrm{X}$ & $\mathrm{X}$ & $\mathrm{X}$ & $\mathrm{X}$ & \\
\hline Szepligetella 243 & 243 & & $X$ & $\mathrm{X}$ & $\mathrm{X}$ & & $\mathrm{X}$ & $\mathrm{X}$ & \\
\hline Szepligetella 247 & 247 & & & & $\mathrm{X}$ & & $\mathrm{X}$ & $\mathrm{X}$ & \\
\hline Szepligetella 248 & 248 & & $X$ & & $\mathrm{X}$ & & $\mathrm{X}$ & $\mathrm{X}$ & \\
\hline Szepligetella sericea & 297 & & & & & X & $\mathrm{X}$ & $\mathrm{X}$ & \\
\hline Szepligetella 047 & 208 & 047 & $\mathrm{D}$ & X & X & & $\mathrm{X}$ & $\mathrm{D}$ & $\mathrm{D}$ \\
\hline Szepligetella 055 & 280 & 055 & & $X$ & $\mathrm{X}$ & & $\mathrm{X}$ & $\mathrm{D}$ & $\mathrm{D}$ \\
\hline Szepligetella 056 & 294 & 056 & $\mathrm{D}$ & $\mathrm{X}$ & $\mathrm{X}$ & $X$ & $\mathrm{X}$ & $\mathrm{X}$ & $\mathrm{D}$ \\
\hline Szepligetella 285 & 285 & & & $\mathrm{X}$ & $\mathrm{X}$ & $\mathrm{X}$ & $\mathrm{X}$ & $\mathrm{X}$ & \\
\hline Trissevania anemotis & 282 & 038 & $\mathrm{D}$ & $\mathrm{X}$ & & $\mathrm{X}$ & $\mathrm{X}$ & $\mathrm{D}$ & $\mathrm{D}$ \\
\hline Trissevania 507 & 507 & & & & & $X$ & & & \\
\hline Zeuxevania 499 & 499 & & & & $\mathrm{X}$ & $\mathrm{X}$ & & & \\
\hline Zeuxevania 500 & 500 & & & & $\mathrm{X}$ & $\mathrm{X}$ & & $\mathrm{X}$ & \\
\hline Zeuxevania 503 & 503 & & & & & $\mathrm{X}$ & & & \\
\hline Zeuxevania 505 & 505 & & $X$ & & $\mathrm{X}$ & $X$ & X & $\mathrm{X}$ & \\
\hline Zeuxevania 015 & 191 & 015 & $\mathrm{D}$ & & $\mathrm{X}$ & & & $\mathrm{D}$ & $\mathrm{D}$ \\
\hline Zeuxevania splendidula & 312 & 031 & $\mathrm{D}$ & & $X$ & $X$ & $X$ & $\mathrm{X}$ & $\mathrm{D}$ \\
\hline$\%$ amplified & & & 71 & 44 & 66 & 64 & 67 & 86 & 50 \\
\hline$\%$ parsimony-informative & & & 40 & 44 & 49 & 53 & 35 & 60 & 40 \\
\hline
\end{tabular}

Table 1. Taxonomic and genetic sampling. Exemplars used by Deans et al. (2006) are listed with the reference from that paper (DV\#) beside the internal voucher number (Ext.) Genes for each taxon are marked with an $\mathbf{X}$ if amplified in this study and $\mathbf{D}$ if amplified by Deans et al. (2006). Gene codes: $28 \mathrm{~S}=$ 28S rDNA; AM2 = alpha-mannosidase II; CAD1 and CAD2 = carbamoyl-phosphate sythetase-asparate transcarbamoylase-dihydroorotase (CAD) (for amplicon regions for each segment, see Figure 1); RPS23 $=$ Ribosomal Protein S23; COI = cytochrome oxidase I; 16S = 16S rDNA. 
undescribed. Several DNA extracts and some sequences were used from Deans et al. (2006), as indicated in Table 1. Vouchers were deposited at the Frost Entomological Museum, at The Pennsylvania State University, or in repositories stipulated by collecting permits and/or loan agreements. See supplementary CSV file (EvaniidPhylogenyVouchers.csv).

\section{Gene selection}

We utilized DNA from six different genes, including two mitochondrial (mt) genes (16S ribosomal DNA $(16 S)$ and cytochrome c oxidase I (COI)) and four nuclear genes (28S ribosomal DNA (28S), ribosomal protein S23 (RPS23), carbamoyl-phosphate synthetase-aspartate transcarbamoylase-dihydroorotase (CAD) and alpha-mannosidase II (AM2)). Diagrams of the gene structures of CAD, RPS23, and AM2 are presented in Figure 1. The diagrams were produced based on annotations of the genomic reference sequences from Apis mellifera Linnaeus, 1758 (NCBI RefSeq ID: GCF_000002195.4) and Nasonia vitripennis (Ashmead, 1904) (NCBI RefSeq ID: GCF_000002325.3), visualized in NCBI's Sequence Viewer (http://www.ncbi.nlm.nih.gov/tools/sviewer) and Geneious v.6.0.6 (Biomatters Ltd.) The annotations include information on the introns, exons, organization of coding regions and protein product features. Conserved domains in the protein products were also identified via a BLASTx search (Altschul et al., 1990) against NCBI's Conserved Domains Database (CDD) (Marchler-Bauer et al., 2015). The genetic regions corresponding to the identified domains are included for reference in the diagrams as well as the primers used in this study (primer sequences are listed in Table S2). Further background about the three protein coding genes is provided below since the amplified regions or genes utilized are novel for phylogenetic studies. All sequences are available in NCBI's Genbank (https: //www.ncbi.nlm.nih.gov/genbank/) under accession numbers KY082187-KY082565.

\section{$C A D$}

$C A D$ is a long and complex gene which codes a "fusion" protein, that is, a protein with multiple enzymatic activities: glutamine-amidotransferase (GATase), carbamoylphosphate synthetase (CPSase), dihydroorotase (DHOase) and aspartate/ornithine transcarbamoylase (ATCase/OTC). There are 26 exons and 25 introns in both Apis and Nasonia, although intron loss has been reported in the CPSase small chain region in some Braconidae (Sharanowski et al. 2011). CPSase is divided in two domains: one for a short chain, which includes GATase, and one for a long chain. The long chain is also subdivided, consisting of two subunits (N-terminal + ATP-binding region), one oligomerization domain, and one MGS-like (methylglyoxal synthetase-like) domain. These two CPSase chains are coded by 14 exons. Various segments of this gene have been used in other phylogenetic studies of insects, particularly for lineages diversifying within the last 150 million years (Danforth et al., 2006; Moulton and Wiegmann, 2004; Winterton and De Freitas, 2006). The regions we analyzed are within the CPSase domains, extending between exons 3 to 5 (Figure 1A).

\section{RPS23}

Ribosomal protein S23 (Figure 1 B) is part of the small ribosomal subunit (Wool, 1979). It has a binding site for mRNA and is associated with the eukaryotic initiation factor of the translation process (NCBICDD:cd03367). This gene has been previously used in macro-evolutionary phylogenetic studies on Hymenoptera (Sharanowski et al. 2010) and Arthropoda (Aleshin et al., 2009, Timmermans et al. 2008) and as an EPIC (exon-primed, intron-crossing) marker for population-level studies (Lohse et al. 2011. 2010). RPS23 is well conserved in sequence and structure across Hymenoptera, with the variation concentrated in the introns. In both Apis and Nasonia, there are three exons (3bp, 159bp, and 270bp in length) and 2 introns (339bp and 84bp in Apis; 353bp and 79bp in Nasonia). The amplified region covers the downstream region of exon 2, full intron 2, and about half of exon 3 , which contains the aminoacyl-tRNA interaction site and therefore is expected to be conserved.

\section{$A M 2$}

We performed sequence similarity searches with tBLASTx (Altschul et al. 1990), using Hymenopteran expressed sequence tags (ESTs) from Sharanowski et al. (2010) against proteins of Apis mellifera and Nasonia vitripennis. Our search focused on genes with regions of variability (for putative phylogenetic signal), limited introns and relatively long exons, and regions of sequence conservation (for priming sites). Alpha-mannosidase II is a glycoside hydrolase involved in the catabolism of carbohydrates (Gonzalez and Jordan, 2000) and has not been explored for phylogenetic studies. There has been a shift in the placement of the second intron between Nasonia and Apis (Figure $1 \mathrm{C}$ ), and thus we labeled the exons $2 \mathrm{a}$ and $2 \mathrm{~b}$ 
to demonstrate the homology with labeled exon 3 in both taxa. Three main protein domain regions are identifiable in the reference sequences: (1) an N-terminal catalytic domain of Golgi alpha-mannosidase II, which is entirely in exon 2a in Apis, but overlaps the second intron in Nasonia, and therefore also lies in exon 2b; (2) a middle domain, which is located in exon 3; and (3) and a C-terminal, which is located in exon 4 (Figure $1 \mathrm{C}$ ). The amplified area is contained in the region that corresponds to the $\mathrm{N}$-terminal in Apis, ending before the second intron (Figure 1C). No intron was amplified in the evanioid taxa used in this study, and thus the gene structure is more similar to Apis in the amplified region.

\section{Extraction and Sequencing}

Extraction of genomic DNA was performed following the manufacturer's protocols using the DNeasy ${ }^{\mathrm{TM}}$ Tissue Kit (Qiagen, USA). Exemplars were either whole body extracted or only the separated thorax and metasoma were used as the use of the head often resulted in low DNA concentrations in Evaniids. COI was amplified using the protocols outlined in Schulmeister et al. (2002), with the primers developed for that study or using the universal primers developed by Folmer et al. (1994) and following protocols outlined in Namin et al. (2014) (Table S2). Sequences for 16S mitochondrial rDNA were used from Deans et al. (2006), which were based on primers and protocols developed in previous studies (Dowton and Austin 1994: Whitfield, 1997). Amplification of the D2-D3 region of $28 S$ was performed using either primers developed byDowton and Austin (2001) or primers newly developed for this study (Table S2), due to difficulty with amplification of some taxa. $C A D$ sequences were amplified in two discontinuous fragments using newly developed primers (Figure 11, Table S2: $C A D 1, C A D 2$ ). For $C A D 1$, three reverse primers were developed to either reduce degeneracy or due to amplification difficulties in some taxa, and a touchdown protocol was also used to increase specificity of the reaction (Table S2). For CAD2, two sets of primers were developed, the second set (CAD-Amel379F/CAD-Amel479R) slightly internal to the first (CAD-Amel368F/CAD-Amel482R). If no amplification product was achieved with the first set of primers, the second set was used alone or as a nested re-amplification of the product obtained with the first set. RPS23 was amplified using primers developed by Lohse et al. (2011) and in conjunction with a second newly developed reverse primer and amplified with a touchdown protocol (Figure 11B; Table S2). Primers were also designed to amplify AM2, with an internal forward primer (AM2-Amel356F) amplifying a much shorter fragment (Figure $1 \mathrm{C}$, Table S2), which increased the number of taxa for which we achieved amplification success.

All PCR amplifications were carried out using 0.2-1 $\mu \mathrm{g}$ DNA extract, $1 \times$ Standard Taq Buffer $($ New England Biolabs, USA) (10 mm Tris-HCl, $50 \mathrm{~mm} \mathrm{KCl,} 1.5 \mathrm{~mm} \mathrm{MgCl2}), 200 \mu \mathrm{m} \mathrm{dNTP}, 4 \mathrm{~mm} \mathrm{MgSO} 4$, $400 \mathrm{~nm}$ of each primer, 1 unit of Taq DNA polymerase (New England Biolabs, USA) and purified water to a final volume of $25 \mu \mathrm{L}$. PCR products were visualized on a $1 \%$ agarose gel. Occasionally $5 \%$ Dimethyl sulfoxide (DMSO, Sigma-Aldrich, USA) was added as a PCR additive when non-specific bands occurred. This additive has been shown to increase PCR yield with GC-rich templates (Farell and Alexandre, 2012). Nested re-amplifications were performed using $0.5 \mu \mathrm{L}$ of PCR product as DNA template (concentrations varied depending on first PCR reaction success). PCR purification was performed using ExoSAP-IT (Affymetrix, USA) following the manufacturer's instructions, except using $25 \%$ of the suggested reagent amount. If double bands were visualized on the gel following PCR, a subsequent $50 \mu \mathrm{L}$ reaction was run on gel cut bands, the product ran on a 2.5\% agarose gel, and purified using the QIAquick Gel Extraction Kit (Qiagen, USA) following the manufacturer's protocols. Sequencing was carried out using the BigDye Terminatorv 3.1 Cycle Sequencing Kit (Applied Biosystems, U.S.A.), with reaction products sequenced on an Applied Biosystems 3730xl DNA Analyzer at the Genomic Sciences Laboratory, North Carolina State University. Contigs were assembled and trimmed for quality using Geneious.

\section{Sequence alignment}

The protein-coding genes were aligned by translating the sequences and setting the correct reading frame in BioEdit (Hall, 1999). Sequences were then aligned as proteins using MAFFT (Katoh and Standley, 2013) on the EMBL-EBI webserver (Li et al. 2015) under default settings and then back translated to nucleotides. Introns present in $C A D I$ and $R P S 23$ were excluded from the dataset prior to multiple sequence alignment. Ribosomal DNA sequences were aligned following secondary structure models developed by Gillespie et al. (2005a b) and modified by Deans et al. (2006) for Evaniidae. Regions of ambiguous alignment (RAA), expansion and contraction (REC), and slipped-strand compensation (RSC) were excluded from the analysis, following Deans et al. (2006). For analysis of sequence motifs, intron 
were aligned using MAFFT with a gap opening penalty of 2 and gap extension penalty of 0.5 to limit excessive gaps in the alignment.

\section{Phylogenetic analyses}

The optimal partitioning scheme and models of evolution for the concatenated analysis were determined using PartitionFinder v.1.1.1 (Lanfear et al., 2012). Character sets were predefined by gene, and by codon position for the 5 protein-coding genes for a total of 17 partitions (CAD1 and CAD2 were partitioned separately). The Bayesian information criterion was used to select among models implemented in MrBayes version 3.2 Ronquist et al. (2012b), with the greedy search algorithm and branch lengths unlinked. The optimal scheme included two partitions. The first partition included the 3rd codon positions for $C A D 1, C A D 2, A M 2$, and RPS23 under the Hasegawa-Kishino-Yano model (Hasegawa et al., 1985). The remaining 13 predefined partitions were included together under the general time reversible model (GTR). Both partitions included a parameter for invariant sites and rate heterogeneity modeled under a gamma distribution. We observed notable differences in nucleotide composition across taxa for some genes (calculated in MEGA v.6 Tamura et al. 2013), and thus, tested for base composition homogeneity using chi-square tests in PAUP* (Swofford, 2002) (Supplementary Material Table S3). For CAD1 and RPS23 the intron was removed.

Phylogenies were estimated using MrBayes 3.2, either on the CIPRES Science Gateway (Miller et al. 2010) or the ComputeCanada WestGrid computational facility. Parameters were unlinked and site specific rates were allowed to vary across partitions. Analyses were performed with two independent searches and four chains. All concatenated analyses were run for 10 million generations, sampling every 2000th generation. Individual gene trees were analyzed with 5 million generations, sampling every 1000th. Convergence diagnostics, stationarity, and appropriate mixing were assessed with Tracer v1.6 (Rambaut and Drummond, 2009), and a suitable burn-in was chosen based on the parameter values. Trees from the posterior distribution were summarized post burn-in with a majority rule consensus and manipulated for better visualization using FigTree v.1.3.1 (Rambaut, 2012) and modified for publication using Adobe Illustrator (Adobe Systems, Inc. San Jose, CA). The final nexus file is available through Penn State's ScholarSphere repository (DOI: 10.18113/S1D06H).

\section{Divergence time estimations}

An uncorrelated log-normal relaxed clock as implemented in the program BEAUTi and BEAST v.1.8.2 (Drummond et al. 2002, 2012) was used to estimate divergence times. The same partitions and models of molecular evolution were applied to each partition as in the phylogenetic analysis. We utilized the Birth-Death process for incomplete sampling (Stadler, 2009) and started with a random tree. Only the calibration for the entire ingroup (Evaniidae) was constrained to be monophyletic which was well supported from the Bayesian analysis.

We utilized six fossil calibration points with each fossil assigned to the crown group for which they belonged (see Fossil Calibrations in Supplementary Material) (Brues, 1933, Nel et al. 2002: Peñalver et al. 2010, Jennings et al. 2004, 2013; Jennings and Krogmann, 2009; Rasnitsyn et al., 1998; Sawoniewicz and Kupryjanowicz, 2003). We performed two separate analyses to examine uncertainty with respect to maximum bounds for clade ages. For the first analysis we used log-normal distributions. The age of the fossil determined the hard minimum bound, as the clade to which it belongs must be at least that old. We then chose a mean and standard deviation so that the $95 \%$ highest priority density interval (95\% HDP) for the divergence estimation of the clade was from 2 to 25 million years prior to the age of the fossil. The 25 million year demarcation is arbitrary, but it seems reasonable and follows Cardinal and Danforth (2013). For the second analysis we chose hard maximum bounds based on previous knowledge of the fossil record and the evolutionary relationships among the included taxa, which are justified (Supplementary Material - Fossil Calibrations) for each calibration. Generally, we chose the mean as the average between the hard minimum and maximum bounds and then set the standard deviation so that the 95\% HDP spanned the range from the minimum to the maximum bound. For both analyses, initial values were set to the mean and the ucld.mean prior was set to exponential with a mean of 0.05 . Although these values are somewhat arbitrary, according to the authors of the program, they are unlikely to have an effect on the analysis (Drummond and Rambaut, 2007; Drummond et al., 2012). All other parameters and the Markov-chain Monte Carlo settings were left at the default settings. The xml input files for both the lognormal and normal distribution analyses are available through Penn State's ScholarSphere repository (DOI: $10.18113 / \mathrm{S} 1 \mathrm{D} 06 \mathrm{H}$ ). 


\section{RESULTS AND DISCUSSION}

\section{Phylogenetic analyses}

The final concatenated data set consisted of 3097 characters total: COI (681bp), $16 S$ (371bp, excluding RAAs), $28 S$ (428bp, excluding RAAs), AM2 (672bp), CAD1 (417bp, excluding the intron), CAD2 (321bp), and RPS23 (207bp, excluding the intron). Individual gene trees are depicted in Supplementary Figures S1-S7. The null hypothesis for base composition homogeneity was rejected for $A M 2(\chi 2=368.819$, $\mathrm{df}=120 ; \mathrm{P}=0.000000000)$ and $\mathrm{COI}(\chi 2=562.535, \mathrm{P}=0.0000000)$ (Table S3). Average nucleotide composition across all genes and gene regions analyzed are depicted in Table S3.

The Bayesian analysis of the concatenated dataset recovered a well resolved tree with most clades well supported ( $\mathrm{pp}>0.95$ ) (Figure 2). Clades recovered across the individual gene trees and for the concatenated analysis are summarized in Table S4 and gene trees are depicted in Figures S1-S7. We also performed a Maximum Likelihood analysis with RaxML v8.2.4 (Stamatakis, 2014, 2006) (Figure S15) under the GTR+CAT model and auto-determination of bootstrap replicates. The phylogenies obtained from BEAST (Figure 3), Mr.Bayes (Figure 2), and RaxML (Figure S15) were very similar except relationships among species varied within genera and Micrevania was not monophyletic in the Bayesian analysis (Figure 2). The placement of Rothevania also varied across analyses.

In the concatenated analysis (Figure 2), Evaniidae was recovered as monophyletic with high support ( $\mathrm{pp}=1.0)$. Of the 15 genera included in the analysis with more than one representative, nine were recovered as monophyletic, including Evaniscus, Decevania, Semaeomyia, Evania, Hyptia, Brachygaster, Prosevania, Trissevania, and Evaniella. All clades representing monophyletic genera had posterior probabilities of 1.0. Although Micrevania was recovered as paraphyletic, it was recovered as monophyletic in other analyses, as mentioned above, the divergence analysis (Figure 3), ML analaysis (Fig S.15) and the $16 S$ and COI individual gene analyses (Table S3) and previously by Deans et al. (2006).

Similar to the previous study (Deans et al. 2006), Parevania and Zeuxevania were recovered as paraphyletic with respect to each other, but in a well-supported clade $(\mathrm{pp}=1.0)$ with Papatuka, in the concatenated analysis as well as five of the seven gene trees (Table S4). Interestingly, all of these taxa have a distinct sequence motif at the 3' end of the RPS23 intron: GTTTGTTTTGYAG (Fig. S9). No other evaniid taxa have a similar motif at the 3' end (Fig. S8), and thus the motif is diagnostic for this clade. Trissevania and Evania were recovered as sister taxa with high support $(\mathrm{pp}=1.0)$ in the concatenated analysis and these two taxa were recovered as sister to Zeuxevania + Parevania + Papatuka $(\mathrm{pp}=0.98)$ (Figure 2). But there was little support for these higher level relationships among in the individual gene trees (Table S4). Brachygaster was recovered as sister to Prosevania with strong support $(\mathrm{pp}=1.0)$ but was only recovered in the $C A D 2$ gene tree (Fig. S4). Micrevania was also recovered as the sister to all remaining evaniids, followed by Brachygaster + Prosevania in the concatenated analysis. Yet, the position of these taxa fluctuated widely among the individual gene trees, likely due to inconsistent taxon sampling across the gene trees.

Acanthinevania and Szepligetella were consistently recovered together ( $\mathrm{pp}=1.0$ in the concatenated analysis (Figure 2) and all gene trees except $16 S$ (Table S4), but were paraphyletic with respect to each other. Interestingly, all members of Acanthinevania and Szepligetella have a GATCTAAC motif (Fig. S10) in the RPS23 intron that is not shared with any other evaniid taxa (Fig. S8), highlighting their close evolutionary relationship. There are also two diagnostic motifs within regions of ambiguous alignment (RAAs) that were excluded from the phylogenetic analyses. All members of Acanthinevania and Szepligetella have the motif TAAAAT in RAA8 (Fig. S11) and the motif TGCAYT within RAA12 (Fig. S12). Evaniella was recovered as the sister group to Acanthinevania + Szepligetella in the concatenated analysis and in three genes trees (Table S4). Members of all three genera share a 9bp diagnostic motif in RAA10 in 28S: YTCGAWAAA (Fig. S12). Most other evaniid taxa do not have this many base pairs in this position (usually $2-4 \mathrm{bp}$ ); the ones that do have longer motifs are radically different in sequence (the full alignment is available in Scholarsphere, DOI:10.18113/S1D06H). Alobevania was recovered as sister to Evaniella + (Acanthinevania + Szepligetella), with strong support in the concatenated analysis, and with moderate support ( $\mathrm{pp}=0.88$ ) in the $28 S$ gene tree. This result is unsurprising given that these taxa were once treated as Evaniella (Deans and Huben, 2003).

New world taxa with reduced wing venation (Evaniscus, Decevania, Hyptia, Rothevania, and Semaeomyia) are recovered together in a well-supported clade $(\mathrm{pp}=1.0)$, in the concatenated analysis (Figure 2). This clade is only recovered in the CAD1 gene tree (Figure S4), possibly due to lower taxonomic sampling in some individual gene trees due to failed amplification. However, these taxa are present 
in various combinations throughout the individual gene trees, but the relationships among taxa fluctuate widely, which is also reflected in the lower support values in the concatenated tree for relationships among these genera (Figure 2).

\section{Divergence time analyses}

The phylogenies obtained from the two Bayesian uncorrelated relaxed clock analyses using BEAST were both identical (Figure 3 (simplified chronogram from the log-normal distribution) and Fig S14 (normal distribution)). Other than slight differences among species within genera, and the recovery of Micrevania as monophyletic, the trees were very similar to the tree obtained from the analysis with MrBayes (Figure 2). Estimates of divergence time from both analyses, using either a log-normal and normal distribution are listed in Table 2 . The log-normal analysis estimated younger divergence times for all clades (Table 2). This was expected as the calibration bounds were constrained within 25 million years of the fossil's age in the log-normal analysis, but were allowed to vary across a larger span of time in the normal distribution analysis based on interpretations of the fossil record. It is likely that the normal analysis uses too broad a range, with the maximum bound being set too far away from the oldest known fossil for the crown lineage, and thus we depict the log-normal analysis (Figure 3) and use these dates to draw inferences about evaniid clade divergence. Evaniidae was estimated to diverge around 137 million years ago (Mya) (134.1-141.1). Although the superfamily was not the focus of this study, Evanioidea had an estimated mean age of 168 Mya (135.9-199.0), consistent with other previous estimates suggesting Evanioidea diverged in the mid-late Jurassic (Peters et al., 2017; Branstetter et al., 2017). Branches leading to Micrevania, Prosevania, and Brachygaster split sometime around the end of the Cretaceous, with means ranging between 60-73 Mya (Table 2). Other extant genera likely diverged sometime in the early Cenozoic and these lineages were likely all present before the start of the Neogene (Figure 3, Table 2).

\begin{tabular}{l|l|l} 
& $\begin{array}{l}\text { Log-normal - Age (My) } \\
\text { mean }(95 \% \text { HDP) }\end{array}$ & $\begin{array}{l}\text { Normal - Age (My) } \\
\text { mean }(95 \% \text { HDP) }\end{array}$ \\
\hline $\begin{array}{l}\text { Gasteruption (Gasteruptiidae) } \\
\text { Pristaulacus (Aulacidae) }\end{array}$ & $38.6(18.5-59.3)$ & $46.3(27.2-69.4)$ \\
Evaniidae & $49.1(45.4-54.7)$ & $48.9(23.3-73.6)$ \\
Brachygaster & $\mathbf{1 3 6 . 8 ( 1 3 4 . 1 - 1 4 1 . 4 )}$ & $\mathbf{1 5 1 . 5}(\mathbf{1 3 5 . 9 - 1 6 6 . 7 )}$ \\
Decevania & $30.7(40.5-86.4)$ & $72.1(49.5-96.3)$ \\
Evania & $45.6(25.2-51.1)$ & $47.8(31.6-64.0)$ \\
Evaniella & $69.3(55.5-84.6)$ & $55.4(40.5-70.7)$ \\
Evaniscus & $66.0(40.8-89.5)$ & $88.6(73.5-104.3)$ \\
Hyptia & $50.7(45.7-57.8)$ & $80.4(50.1-110.3)$ \\
Micrevania & $67.8(38.4-94.8)$ & $65.4(50.7-81.2)$ \\
Prosevania & $72.1(58.6-86.4)$ & $80.1(52.5-111.8)$ \\
Semaeomyia & $59.0(46.6-72.5)$ & $75.7(67.6-103.8)$ \\
Szepligetella s.l. & $49.0(38.3-60.1)$ & $60.6(48.1-94.0)$ \\
Trissevania & $32.0(17.5-50.4)$ & $38.5(20.5-57.3)$ \\
Zeuxevania s.l. & $55.6(45.8-66.3)$ & $76.0(59.6-92.2)$
\end{tabular}

Table 2. Estimates of divergence times for Evaniidae (bolded) and outgroups based on an uncorrelated log-normal relaxed clock analyses. Six fossil calibrations were used (see Supplementary Material) with maximum bounds for clade ages set using a log-normal (Analysis 1) and normal distribution (Analysis 2). For each analysis the mean age in millions of years (My) and the 95\% highest posterior density interval (HDP, equivalent to a confidence interval) is provided.

\section{Novel genes and molecular signatures}

Alpha-mannosidase 2 (AM2) has never been used before in phylogenetic studies. This gene has a mix of conserved and variable sites (44\% parsimony-informative sites), but it failed the test for base composition homogeneity, which can cause systematic bases in phylogenetic analyses (Phillips et al. 2004, RodríguezEzpeleta et al. 2007; Sharanowski et al. 2011). RY-coding this gene did not change the results obtained 
from the concatenated analysis. Unfortunately amplification of $A M 2$ was difficult, even with the addition of PCR additives such as DMSO, causing a high amount of missing data. Gel cuts were often necessary to achieve clean sequences for several genes, but particularly AM2. RPS23 was highly conserved in the exonic regions, and thus may be better suited for deeper level studies across families. There were distinct molecular signatures within the intronic region that would be very useful for lower level studies, such as across species, or population-level studies (see Lohse et al. 2010). The molecular motifs in the RPS23 intron were useful for delimiting genera and diagnosing congenerics (see taxonomic implications, below). The individual gene trees for both regions of $C A D$ were relatively well resolved (Figures S4-5) and similar to other studies (Desjardins et al. 2007; Sharanowski et al. 2011), which demonstrates good utility for resolving phylogenetic relationships in Hymenoptera.

Alignments based on secondary structure for rDNA have been very useful for delimiting highly variable regions to exclude from analyses to achieve better phylogenetic results (Gillespie et al. 2005b, Pitz et al. 2007). However, variable regions have useful information with phylogenetic and taxonomic utility, as demonstrated by Sharanowski et al. (2011), who included variable regions (RECs, RAAs, and RSCs) if the variation in sequence length had a standard deviation less than one. Here we demonstrate the utility of some of these regions for diagnosing genera (Figures S11-12) and use these data to improve taxonomic classifications (see Taxonomic implications below).

\section{Taxonomic implications}

Relative to the Deans et al. (2006) study, the addition of several more genes and taxa clearly led to increased resolution. For example, an additional four genera were recovered as monophyletic, and higher level relationships were more resolved and better supported. Our understanding of evaniid relationships remains incomplete, but, based on mounting evidence here and through our observations of morphology, we feel comfortable proposing the following classificatory changes.

New synonyms of Zeuxevania and new combinations Parevania, syn. nov., and Papatuka, syn. nov., are congeneric with and junior synonyms of Zeuxevania. Bradley (1908) also suspected that these two taxa were congeneric and treated Parevania as a subgenus of Zeuxevania. These taxa are consistently recovered together in well-supported clades across individual gene trees and within the concatenated analyses, but are polyphyletic with respect to each other (Table S4). Additionally, there are molecular signatures within the RPS23 intron that support their shared evolutionary history (Fig. S9). ARD has observed thousands of specimens of these taxa and can find no consistency in the presence or absence of the fore wing vein 1RS, which was the only character purported to separate Parevania and Zeuxevania (Deans and Huben, 2003).

Following the taxonomy of Hedicke (1939), we hereby transfer the following species back to Zeuxevania: albitarsus (Cameron, 1899); annulicornis (Turner, 1927); atra (Kieffer, 1916); bisulcata (Kieffer, 1911); curvicarinata (Cameron, 1899); kriegeriana (Enderlein, 1905); leucostoma (Kieffer, 1910); longicalcar (Kieffer, 1911); punctatissima (Kieffer, 1911); rubra (Cameron, 1905); sanguineiceps (Turner, 1927); schlettereri Bradley 1908; schoenlandi (Cameron, 1905); semirufa (Kieffer, 1907).

We also transfer the following species to Zeuxevania for the first time: aurata (Benoit, 1950), comb. nov.; brevis (Brues, 1933), comb. nov.; broomi (Cameron, 1906), comb. nov.; emarginata (Kieffer, 1911), comb. nov.; kasauliensis (Muzaffer, 1943), comb. nov.; laeviceps (Enderlein, 1913), comb. nov.; madegassa (Benoit, 1952), comb. nov.; meridionalis (Cameron, 1906), comb. nov.; micholitzi (Enderlein, 1905), comb. nov.; ortegae (Ceballos, 1966), comb. nov.; plana (Benoit, 1952), comb. nov.; producta (Brues, 1933), comb. nov.; remanea (Brues, 1933), comb. nov..

Papatuka was originally described from a single, apterous specimen (Deans, 2002) and was since expanded to include other, winged species (Deans, 2005). The morphology of these species, which is also reflected in the molecular data, is not substantially different from Zeuxevania, and we transfer those species to Zeuxevania: alamunyiga (Deans, 2002), comb. nov.; capensis (Schletterer, 1886), comb. nov.; longitarsis (Kieffer, 1904), comb. nov.

New synonym of Szepligetella and new combinations There is also abundant evidence to support Acanthinevania as congeneric with Szepligetella. They are consistently recovered together in a clade but neither appears to be monophyletic by itself (Table S4). The primary diagnostic characters that separated these two primarily Australian genera include: Szepligetella with the third labial palpomere swollen; Acanthinevania with an elongated head relative to Szepligetella; and Acanthinevania with labium folded 
strongly anteriorly and thus appearing long and narrow, not broad and flat as in most Szepligetella (Deans and Huben 2003). Our observations of more than 1,000 specimens reveal that these character states (e.g., face long vs. face short) fall along phenotypic gradients, with no discrete sets of states. Several molecular characters link (but do not separate) these genera, including motifs present in the RPS23 intron and at least two regions of 28S (Figs S10-12).

We treat Acanthinevania, syn. nov., as Szepligetella and transfer the following species to Szepligetella: australis (Schletterer, 1886), comb. nov.; braunsi (Kieffer, 1911), comb. nov.; braunsiana (Kieffer, 1911), comb. nov.; clavaticornis (Kieffer, 1911), comb. nov.; erythrogaster (Kieffer, 1904), comb. nov.; eximia (Schletterer, 1886), comb. nov.; genalis (Schletterer, 1886), comb. nov.; humerata (Schletterer, 1889), comb. nov.; leucocras (Kieffer, 1911), comb. nov.; longigena (Schletterer, 1889), comb. nov.; lucida (Schletterer, 1889), comb. nov.; mediana (Schletterer, 1889), comb. nov.; princeps (Westwood, 1841), comb. nov.; quinquelineata (Kieffer, 1904), comb. nov.; rufiventris (Kieffer, 1911), comb. nov.; scabra (Schletterer, 1889), comb. nov.; sericans (Westwood, 1851), comb. nov.; striatifrons (Kieffer, 1904), comb. nov.; szepligeti (Bradley, 1908), comb. nov.; versicolor (Kieffer, 1904), comb. nov.; villosicrus (Kieffer, 1904), comb. nov.

Emerging tribal classification A new tribal classification for Evaniidae is warranted, given the lack of support for Bradley's (1908) original (>100 year-old) tribal concepts (Deans, 2005; Deans et al., 2006; Deans and Huben 2003). Mikó et al. (2014) recently described Trissevaniini, to include Trissevania and Afrevania, and, based on our results here, molecular work by (Deans et al., 2006), and prior morphological work by us and our colleagues (Deans and Huben, 2003; Deans and Kawada, 2008; Kawada and Azevedo 2007, Kawada, 2011) we have an opportunity to revise Hyptiini to include those New World genera with reduced wing venation: Evaniscus, Hyptia, Rothevania, Semaeomyia, and Decevania. We remove Brachygaster, Evaniella, and Zeuxevania from Hyptiini (see Bradley, 1908). This updated concept of Hyptiini can be separated from other evaniid taxa by the absence of at least the fore wing RS+M, and usually many other apical veins (see Figs. 1, 9, 11, 16, 17 in Deans and Huben, 2003), and its origin in the New World.

\section{Evaniid divergence and evolution}

Evaniids diverged in the Early Cretaceous (ca. 134.1-141.1 Mya), when numerous modern cockroach fossils have been found (Grimaldi and Engel 2005), although cockroaches with oothecae are thought to have much earlier origins in the Late Carboniferous (Legendre et al. 2015). Most of the extant evaniid genera diverged sometime near the K-T boundary, which may indicate that the mass extinction played a role in the divergence of multiple new lineages of ensign wasps. Whether or not there has been co-cladogenesis with modern cockroach lineages remains to be tested but would be hampered by the lack of known host relationships for most evaniids (Deans, 2005). For evaniids, as for most Hymenoptera, basic natural history research is needed to understand the trophic relationships among wasps and their hosts.

\section{CONCLUSION}

We provide here a more robust and well-resolved phylogeny for Evaniidae than previous studies, which will facilitate ongoing evolutionary and taxonomic work. Indeed, the new synonyms and combinations proposed above help us progress towards a stable classification that reflects evolutionary relationships. Building on prior results (Deans et al. 2006), our data also reveal new, useful markers for Hymenoptera (AM2 and RPS23) and continue to support the utility of shared molecular motifs in defining major clades in Evaniidae. Our results indicate that Evaniidae diverged in the early Cretaceous with most genera diversifying in the late Cretaceous or early Tertiary. The results also highlight important targets for future data collection, especially near the base of the tree (Micrevania) and the relationships within each genus. More intensive sampling, especially with the addition of morphological data and fossils (e.g., Ronquist et al. 2012a), is the logical next step in providing a tribal classification and more refined estimates for divergence times.

\section{ACKNOWLEDGMENTS}

We are grateful to Mike Irwin, Martin Hauser, Kevin Holston, Jack Longino, Mike Sharkey, the late Evert Schlinger, the late Don Webb, and countless other collectors who shared material with us. We also thank 
the numerous loan facilitators, without whom this work would be impossible and the three reviewers who helped improved the manuscript.

\section{REFERENCES}

Aleshin, V., Mikhailov, K., Konstantinova, A., Nikitin, M., Rusin, L. Y., Buinova, D., Kedrova, O., and Petrov, N. (2009). On the phylogenetic position of insects in the Pancrustacea clade. Molecular Biology, 43(5):804-818.

Altschul, S. F., Gish, W., Miller, W., Myers, E. W., and Lipman, D. J. (1990). Basic local alignment search tool. Journal of molecular biology, 215(3):403-410.

Balhoff, J. P., Mikó, I., Yoder, M. J., Mullins, P. L., and Deans, A. R. (2013). A semantic model for species description applied to the ensign wasps (Hymenoptera: Evaniidae) of New Caledonia. Systematic Biology, 62(5):639-659.

Bradley, J. C. (1908). The Evaniidæ, ensign-flies, an archiac family of Hymenoptera. Transactions of the American Entomological Society, 34(2):101-194.

Branstetter, M. G., Danforth, B. N., Pitts, J. P., Faircloth, B. C., Ward, P. S., Buffington, M. L., Gates, M. W., Kula, R. R., and Brady, S. G. (2017). Phylogenomic insights into the evolution of stinging wasps and the origins of ants and bees. Current Biology, 27(7):1019-1025.

Brues, C. T. (1933). The parasitic Hymenoptera of the Baltic amber. part 1. Bernstein-Forschungen, 3:4-172.

Cardinal, S. and Danforth, B. N. (2013). Bees diversified in the age of eudicots. Proceedings of the Royal Society of London B: Biological Sciences, 280(1755).

Danforth, B. N., Fang, J., and Sipes, S. (2006). Analysis of family-level relationships in bees (Hymenoptera: Apiformes) using $28 \mathrm{~S}$ and two previously unexplored nuclear genes: CAD and RNA polymerase II. Molecular Phylogenetics and Evolution, 39(2):358-372.

Deans, A. and Huben, M. (2003). Annotated key to the ensign wasp (Hymenoptera: Evaniidae) genera of the world, with descriptions of three new genera. Proceedings of the Entomological Society of Washington, 105:859-875.

Deans, A. R. (2002). Papatuka alamunyiga Deans, a new genus and species of apterous ensign wasp (Hymenoptera: Evaniidae) from Kenya. Zootaxa, 95(1):1-8.

Deans, A. R. (2005). Annotated catalog of the world's ensign wasp species (Hymenoptera: Evaniidae), volume 34. American Entomological Institute.

Deans, A. R., Basibuyuk, H. H., Azar, D., and Nel, A. (2004). Descriptions of two new Early Cretaceous (Hauterivian) ensign wasp genera (Hymenoptera: Evaniidae) from lebanese amber. Cretaceous Research, 25(4):509-516.

Deans, A. R., Gillespie, J. J., and Yoder, M. J. (2006). An evaluation of ensign wasp classification (Hymenoptera: Evaniidae) based on molecular data and insights from ribosomal RNA secondary structure. Systematic Entomology, 31(3):517-528.

Deans, A. R. and Kawada, R. (2008). Alobevania, a new genus of neotropical ensign wasps (Hymenoptera: Evaniidae), with three new species: integrating taxonomy with the World Wide Web. Zootaxa, 1787:28 44.

Desjardins, C. A., Regier, J. C., and Mitter, C. (2007). Phylogeny of pteromalid parasitic wasps (Hymenoptera: Pteromalidae): initial evidence from four protein-coding nuclear genes. Molecular Phylogenetics and Evolution, 45(2):454-469.

Dowton, M. and Austin, A. D. (1994). Molecular phylogeny of the insect order Hymenoptera: Apocritan relationships. Proceedings of the National Academy of Sciences USA, 91(21):9911-9915.

Dowton, M. and Austin, A. D. (2001). Simultaneous analysis of 16S, 28S, COI and morphology in the Hymenoptera: Apocrita - evolutionary transitions among parasitic wasps. Biological Journal of the Linnean Society, 74(1):87-111.

Drummond, A. J., Nicholls, G. K., Rodrigo, A. G., and Solomon, W. (2002). Estimating mutation parameters, population history and genealogy simultaneously from temporally spaced sequence data. Genetics, 161(3):1307-1320.

Drummond, A. J. and Rambaut, A. (2007). BEAST: Bayesian evolutionary analysis by sampling trees. BMC evolutionary biology, 7(1):214.

Drummond, A. J., Suchard, M. A., Xie, D., and Rambaut, A. (2012). Bayesian phylogenetics with BEAUti and the BEAST 1.7. Molecular biology and evolution, 29(8):1969-1973. 
Folmer, O., Black, M., Hoeh, W., Lutz, R., and Vrijenhoek, R. (1994). DNA primers for amplification of mitochondrial cytochrome c oxidase subunit I from diverse metazoan invertebrates. Molecular marine biology and biotechnology, 3(5):294-299.

Gillespie, J. J., Munro, J. B., Heraty, J. M., Yoder, M. J., Owen, A. K., and Carmichael, A. E. (2005a) A secondary structural model of the 28S rRNA expansion segments D2 and D3 for chalcidoid wasps (Hymenoptera: Chalcidoidea). Molecular Biology and Evolution, 22(7):1593-1608.

Gillespie, J. J., Yoder, M. J., and Wharton, R. A. (2005b). Predicted secondary structure for $28 \mathrm{~S}$ and $18 \mathrm{~S}$ rRNA from Ichneumonoidea (Insecta: Hymenoptera: Apocrita): impact on sequence alignment and phylogeny estimation. Journal of Molecular Evolution, 61(1):114-137.

Gonzalez, D. S. and Jordan, I. K. (2000). The $\alpha$-mannosidases: phylogeny and adaptive diversification. Molecular Biology and Evolution, 17(2):292-300.

Grimaldi, D. and Engel, M. S. (2005). Evolution of the Insects. Cambridge University Press.

Hall, T. A. (1999). BioEdit: a user-friendly biological sequence alignment editor and analysis program for Windows 95/98/NT. In Nucleic acids symposium series, volume 41, pages 95-98. [London]: Information Retrieval Ltd., c1979-c2000.

Hasegawa, M., Kishino, H., and Yano, T.-a. (1985). Dating of the human-ape splitting by a molecular clock of mitochondrial dna. Journal of molecular evolution, 22(2):160-174.

Hedicke, H. (1939). Evaniidae. In Hedicke, H., editor, Hymenoptorum Catalogus Pars 9. Dr. W. Junk, Gravenhage.

Huben, M. (1995). Evaniidae. In Hanson, P. and Gauld, I., editors, The Hymenoptera of Costa Rica, pages 195-199. Oxford University Press.

Jennings, J. T., Austin, A. D., and Stevens, N. B. (2004). Hyptiogastrites electrinus Cockerell, 1917, from Myanmar (Burmese) amber: redescription and its placement within the Evanioidea (Insecta: Hymenoptera). Journal of Systematic Palaeontology, 2(2):127-132.

Jennings, J. T. and Krogmann, L. (2009). A new species of Pristaulacus kieffer (Hymenoptera: Aulacidae) from Baltic amber. Insect Systematics \& Evolution, 40(2):201-207.

Jennings, J. T., Krogmann, L., and Mew, S. L. (2012). Hyptia deansi sp. nov., the first record of Evaniidae (Hymenoptera) from Mexican amber. Zootaxa, 3349(1):63-68.

Jennings, J. T., Krogmann, L., and Priya, P. (2013). Happy birthday Willi Hennig!—Hyptia hennigi sp. nov. (Hymenoptera: Evaniidae), a fossil ensign wasp from Eocene Baltic amber. Zootaxa, 3731:395-398.

Katoh, K. and Standley, D. M. (2013). MAFFT multiple sequence alignment software version 7: improvements in performance and usability. Molecular biology and evolution, 30(4):772-780.

Kawada, R. (2011). Pictorial key for females of Decevania Huben (Hymenoptera, Evaniidae) and description of a new species. ZooKeys, (116):59-84.

Kawada, R. and Azevedo, C. (2007). Taxonomic revision of the neotropical ensign wasp genus Decevania (Hymenoptera: Evaniidae). Zootaxa, 1496(1):1-30.

Lanfear, R., Calcott, B., Ho, S. Y., and Guindon, S. (2012). PartitionFinder: combined selection of partitioning schemes and substitution models for phylogenetic analyses. Molecular biology and evolution, 29(6):1695-1701.

Legendre, F., Nel, A., Svenson, G. J., Robillard, T., Pellens, R., and Grandcolas, P. (2015). Phylogeny of Dictyoptera: dating the origin of cockroaches, praying mantises and termites with molecular data and controlled fossil evidence. Plos ONE, 10(7):e0130127.

Li, L., Rasnitsyn, A. P., Shih, C., Labandeira, C. C., Buffington, M., Li, D., and Ren, D. (2018). Phylogeny of Evanioidea (Hymenoptera, Apocrita), with descriptions of new Mesozoic species from China and Myanmar. Systematic Entomology, 43(4):810-842.

Li, W., Cowley, A., Uludag, M., Gur, T., McWilliam, H., Squizzato, S., Park, Y. M., Buso, N., and Lopez, R. (2015). The embl-ebi bioinformatics web and programmatic tools framework. Nucleic acids research, 43(W1):W580-W584.

Lohse, K., Sharanowski, B., Blaxter, M., Nicholls, J. A., and Stone, G. N. (2011). Developing EPIC markers for chalcidoid hymenoptera from EST and genomic data. Molecular ecology resources, 11(3):521-529.

Lohse, K., Sharanowski, B., and Stone, G. N. (2010). Quantifying the Pleistocene history of the oak gall parasitoid Cecidostiba fungosa using twenty intron loci. Evolution, 64(9):2664-2681.

Marchler-Bauer, A., Derbyshire, M. K., Gonzales, N. R., Lu, S., Chitsaz, F., Geer, L. Y., Geer, R. C., He, J., Gwadz, M., Hurwitz, D. I., Lanczycki, C. J., Lu, F., Marchler, G. H., Song, J. S., Thanki, N., Wang, 
Z., Yamashita, R. A., Zhang, D., Zheng, C., and Bryant, S. H. (2015). CDD: NCBI's conserved domain database. Nucleic Acids Research, 43(D1):D222-D226.

Mardulyn, P. and Whitfield, J. B. (1999). Phylogenetic signal in the coi, 16s, and 28s genes for inferring relationships among genera of Microgastrinae (Hymenoptera; Braconidae): evidence of a high diversification rate in this group of parasitoids. Molecular Phylogenetics and Evolution, 12(3):282-294.

Mikó, I., Copeland, R. S., Balhoff, J. P., Yoder, M. J., and Deans, A. R. (2014). Folding wings like a cockroach: a review of transverse wing folding ensign wasps (Hymenoptera: Evaniidae: Afrevania and Trissevania). PLoS ONE, 9(5):e94056.

Miller, M. A., Pfeiffer, W., and Schwartz, T. (2010). Creating the CIPRES Science Gateway for inference of large phylogenetic trees. In Gateway Computing Environments Workshop (GCE), 2010, pages 1-8. IEEE.

Moulton, J. K. and Wiegmann, B. M. (2004). Evolution and phylogenetic utility of CAD (rudimentary) among mesozoic-aged eremoneuran Diptera (Insecta). Molecular phylogenetics and evolution, 31(1):363-378.

Namin, H. H., Iranpour, M., and Sharanowski, B. J. (2014). Phylogenetics and molecular identification of the Ochlerotatus communis complex (Diptera: Culicidae) using DNA barcoding and polymerase chain reaction-restriction fragment length polymorphism. The Canadian Entomologist, 146(1):26-35.

Nel, A., Martínez-Delclòs, X., and Azar, D. (2002). A new ensign-fly from the Lower-Middle Miocene Dominican amber (Hymenoptera, Evaniidae). Bulletin de la Société entomologique de France, 107(3):217221.

Peters, R. S., Krogmann, L., Mayer, C., Donath, A., Gunkel, S., Meusemann, K., Kozlov, A., Podsiadlowski, L., Petersen, M., Lanfear, R., Diez, P. A., Heraty, J., Kjer, K. M., Klopfstein, S., Meier, R., Polidori, C., Schmitt, T., Liu, S., Zhou, X., Wappler, T., Rust, J., Misof, B., and Niehuis, O. (2017). Evolutionary history of the Hymenoptera. Current Biology, 27(7):1013-1018.

Peñalver, E., Ortega-Blanco, J., Nel, A., and Delclòs, X. (2010). Mesozoic Evaniidae (Insecta: Hymenoptera) in Spanish amber: Reanalysis of the phylogeny of the Evanioidea. Acta Geologica Sinica (English Edition), 84(4):809-827.

Phillips, M. J., Delsuc, F., and Penny, D. (2004). Genome-scale phylogeny and the detection of systematic biases. Molecular biology and evolution, 21(7):1455-1458.

Pitz, K. M., Dowling, A. P., Sharanowski, B. J., Boring, C. A., Seltmann, K. C., and Sharkey, M. J. (2007). Phylogenetic relationships among the Braconidae (Hymenoptera: Ichneumonoidea): A reassessment of Shi, Chen, and van Achterberg (2005). Molecular Phylogenetics and Evolution, 43(1):338-343.

Rambaut, A. (2012). FigTree v. 1. 4. Molecular evolution, phylogenetics and epidemiology. Edinburgh, UK: University of Edinburgh, Institute of Evolutionary Biology.

Rambaut, A. and Drummond, A. (2009). Tracer v1.5. Available athttp://tree.bio.ed.ac.uk/ software/tracer/Accessed 19 February 2018.

Rasnitsyn, A. P., Jarzembowski, E. A., and Ross, A. J. (1998). Wasps (Insecta: Vespida = Hymenoptera) from the Purbeck and Wealden (Lower Cretaceous) of southern England and their biostratigraphical and palaeoenvironmental significance. Cretaceous Research, 19(3-4):329-391.

Rodríguez-Ezpeleta, N., Brinkmann, H., Roure, B., Lartillot, N., Lang, B. F., and Philippe, H. (2007). Detecting and overcoming systematic errors in genome-scale phylogenies. Systematic Biology, 56(3):389399.

Ronquist, F., Klopfstein, S., Vilhelmsen, L., Schulmeister, S., Murray, D. L., and Rasnitsyn, A. P. (2012a). A total-evidence approach to dating with fossils, applied to the early radiation of the Hymenoptera. Systematic Biology, 61(6):973-999.

Ronquist, F., Teslenko, M., Van Der Mark, P., Ayres, D. L., Darling, A., Höhna, S., Larget, B., Liu, L., Suchard, M. A., and Huelsenbeck, J. P. (2012b). MrBayes 3.2: efficient Bayesian phylogenetic inference and model choice across a large model space. Systematic Biology, 61(3):539-542.

Sawoniewicz, J. and Kupryjanowicz, J. (2003). Evaniella eocenica sp. nov. from the Baltic amber (Hymenoptera: Evaniidae). Acta Zoologica Cracoviensia, 46(Suppl. - Fossil Insects):267-270.

Schulmeister, S., Wheeler, W. C., and Carpenter, J. M. (2002). Simultaneous analysis of the basal lineages of Hymenoptera (Insecta) using sensitivity analysis. Cladistics, 18(5):455-484.

Sharanowski, B. J., Dowling, A. P., and Sharkey, M. J. (2011). Molecular phylogenetics of Braconidae (Hymenoptera: Ichneumonoidea), based on multiple nuclear genes, and implications for classification. Systematic Entomology, 36(3):549-572. 
Sharanowski, B. J., Robbertse, B., Walker, J., Voss, S. R., Yoder, R., Spatafora, J., and Sharkey, M. J. (2010). Expressed sequence tags reveal Proctotrupomorpha (minus Chalcidoidea) as sister to Aculeata (Hymenoptera: Insecta). Molecular phylogenetics and evolution, 57(1):101-112.

Stadler, T. (2009). On incomplete sampling under birth-death models and connections to the samplingbased coalescent. Journal of theoretical biology, 261(1):58-66.

Stamatakis, A. (2006). RAxML-VI-HPC: maximum likelihood-based phylogenetic analyses with thousands of taxa and mixed models. Bioinformatics, 22(21):2688-2690.

Stamatakis, A. (2014). Raxml version 8: a tool for phylogenetic analysis and post-analysis of large phylogenies. Bioinformatics, 30(9):1312-1313.

Swofford, D. L. (2002). PAUP* Phylogenetic analysis using parsimony (*and other methods). Version 4 beta. Sunderland, MA: Sinauer Associates Inc, software.

Tamura, K., Stecher, G., Peterson, D., Filipski, A., and Kumar, S. (2013). MEGA6: molecular evolutionary genetics analysis version 6.0. Molecular biology and evolution, 30(12):2725-2729.

Timmermans, M., Roelofs, D., Mariën, J., and Van Straalen, N. (2008). Revealing pancrustacean relationships: Phylogenetic analysis of ribosomal protein genes places Collembola (springtails) in a monophyletic Hexapoda and reinforces the discrepancy between mitochondrial and nuclear DNA markers. BMC Evolutionary Biology, 8(1):83.

Whitfield, J. B. (1997). Molecular and morphological data suggest a single origin of the polydnaviruses among braconid wasps. Naturwissenschaften, 84(11):502-507.

Winterton, S. and De Freitas, S. (2006). Molecular phylogeny of the green lacewings (Neuroptera: Chrysopidae). Austral Entomology, 45(3):235-243.

Wool, I. G. (1979). The structure and function of eukaryotic ribosomes. Annual review of biochemistry, 48(1):719-754.

Zhang, C., Stadler, T., Klopfstein, S., Heath, T., and Ronquist, F. (2015). Total-evidence dating under the fossilized birth-death process. Systematic Biology, 65:228-249. 

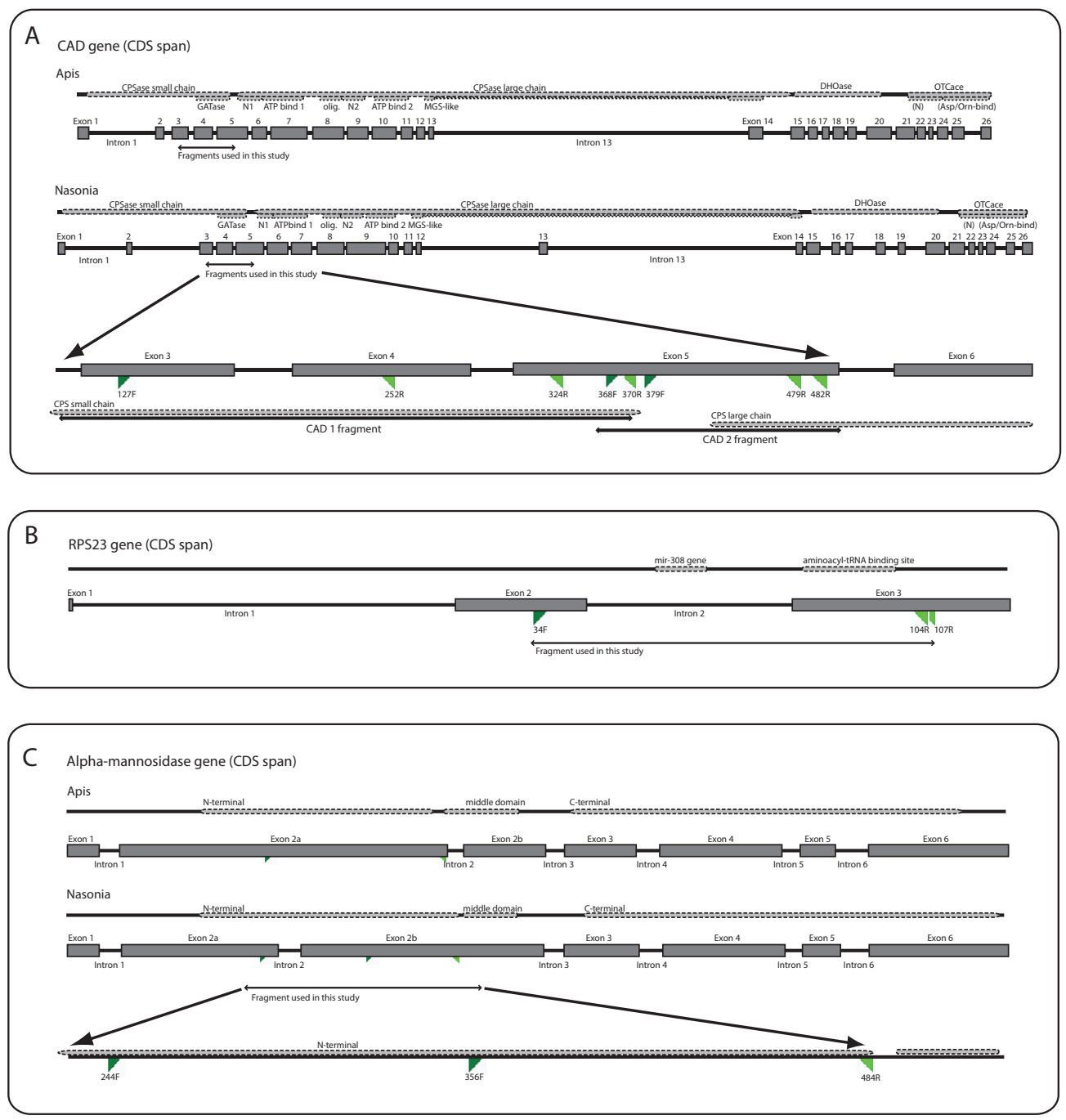

Figure 1. Diagrammatic gene maps for: (A) carbamoyl-phosphate sythetase-asparate transcarbamoylase-dihydroorotase $(C A D)$; (B) ribosomal protein S23 (RPS23); and (C) alpha-mannosidase II (AM2). Dotted lines mark protein domains and features. For $C A D$ and AM2, Apis and Nasonia gene diagrams are shown individually as references due to substantial differences in exon locations. The bottom diagram in each gene map depicts the regions amplified in this study. In CAD, intron 13 in Nasonia has been scaled down due to an incomplete sequence in the GenBank entry. Primers are named according to the amino acid position in the Apis mellifera protein. Forward primers are in dark green and reverse primers in light green. See Table $\mathrm{S} 2$ for primer combinations. Abbreviations: CPS, carbamoyl-phosphate synthase; $G A T$, glutamine aminotransferase; $D H O$, dihydroorotase; $M G S$, methylglyoxal-like; OTC, ornithine carbamoyltransferase; SN1, N-terminal of subunit 1 in CPS large chain; N2, N-terminal of subunit 2 in CPS large chain; olig., oligomerization domain. 


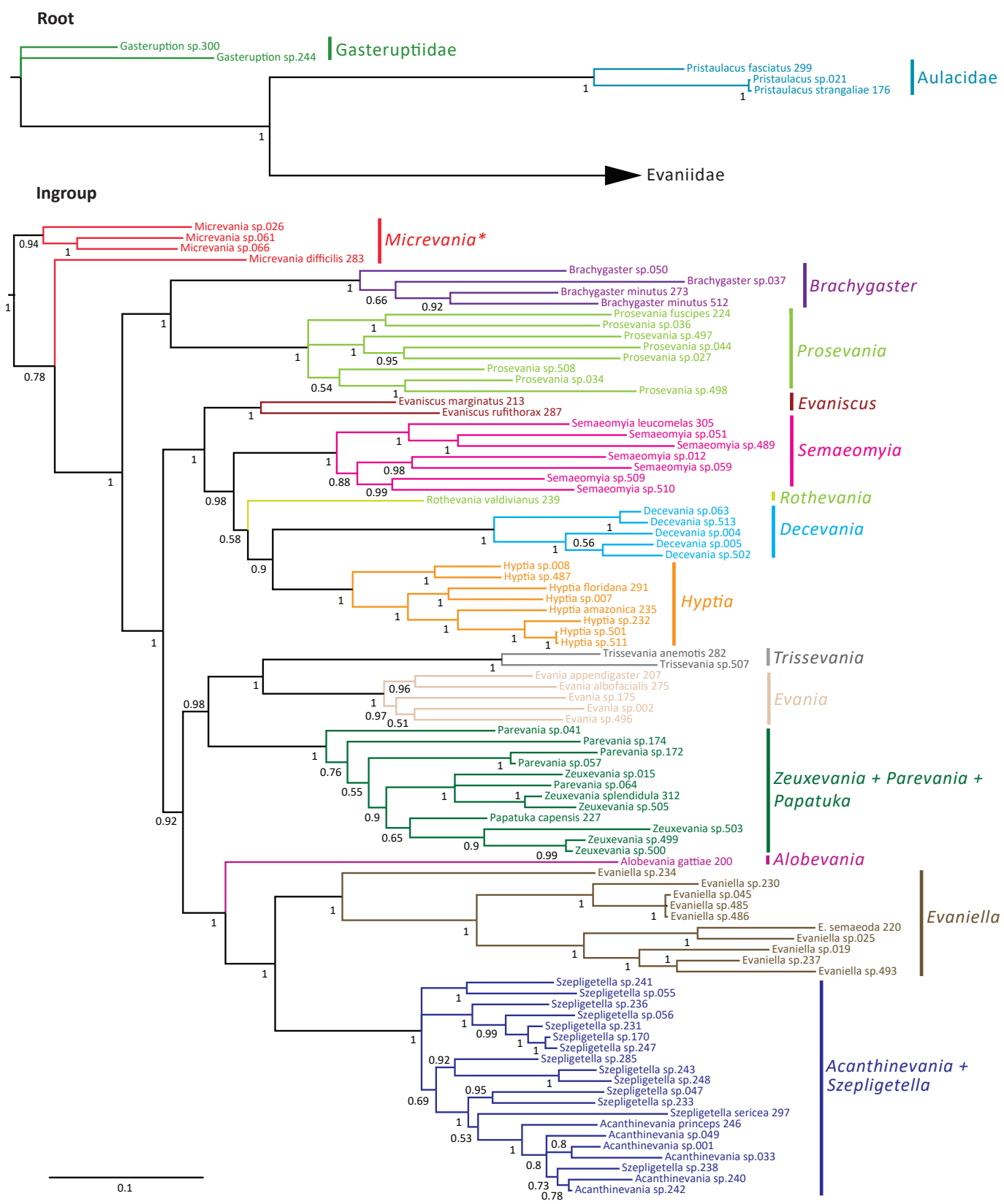

Figure 2. Bayesian analysis of phylogenetic relationships among Evaniidae. The outgroups were removed and placed above the ingroup tree for better visualization (the scale has been retained). Posterior probabilities are listed beside each clade. 


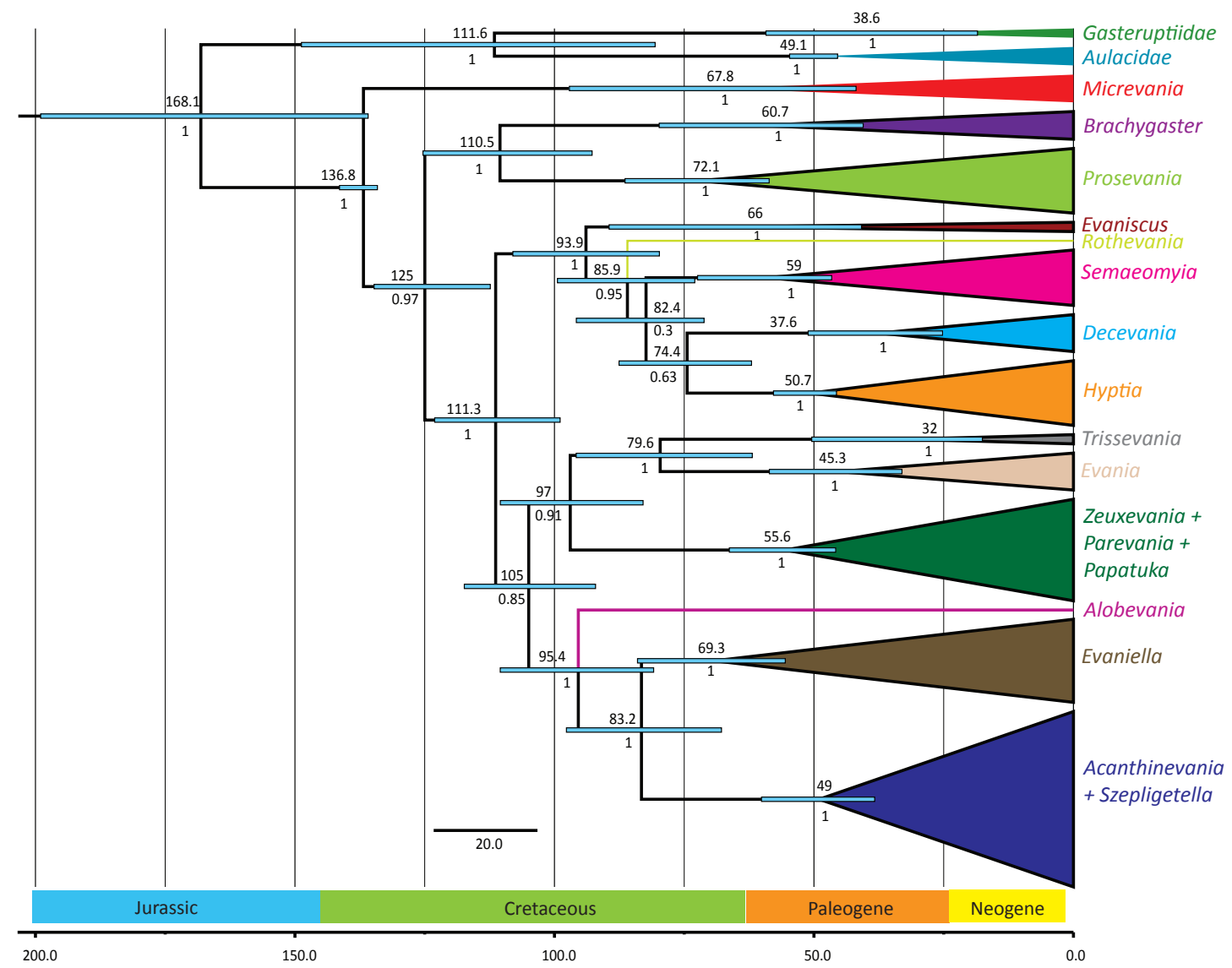

Figure 3. Simplified chronogram showing estimated divergence times for Evaniidae with six fossil calibrations and maximum clade ages under a lognormal distribution. Monophyletic genera have been collapsed for better visualization of the divergence estimations of the major clades. The blue bars indicate the 95\% highest posterior density interval (HDP, also listed in Table 1). The scale is in millions of years. Mean age is listed above each clade and posterior probabilities are listed below . 